\title{
Coptidis Rhizoma induces intrinsic apoptosis through BAX and BAK activation in human melanoma
}

\author{
XIAOOU XU, SATORU YOKOYAMA, YOSHIHIRO HAYAKAWA and IKUO SAIKI \\ Division of Pathogenic Biochemistry, Institute of Natural Medicine, University of Toyama, Toyama 930-0194, Japan
}

Received October 4, 2016; Accepted March 15, 2017

DOI: $10.3892 /$ or.2017.5672

\begin{abstract}
Malignant melanoma has exhibited a rising incidence in recent years worldwide. Although various molecular targeted drugs are being researched and developed for melanoma patients, their efficacy appears to be unsatisfactory. Over the past few years, several reports have demonstrated that Coptidis Rhizoma water extracts (CR) or its major active chemical component, berberine, has anticancer activities in various types of cancer, including melanoma. However, their underlying mechanisms have not been well understood. In the present study, we determined that CR suppressed melanoma cell viability, which was mainly mediated through apoptosis. In addition, the expression levels of anti-apoptotic proteins, BCL2A1, MCL1 and BCL-w, were strongly suppressed by CR treatment. Furthermore, multi-domain pro-apoptotic proteins BAX and BAK were activated by CR treatment and were also required for the $\mathrm{CR}$-induced apoptosis. Collectively, $\mathrm{CR}$ or some formulations containing CR, may be effective safe treatment strategies for human melanoma.
\end{abstract}

\section{Introduction}

Malignant melanoma is an aggressive form of skin cancer that develops from the pigment-producing cells, melanocytes. It has become more and more common worldwide (1). It is also estimated that 76,380 new cases of melanoma were diagnosed in 2016 (2). Only early-staged melanomas can be successfully treated, mainly through surgical excision. BRAF mutations occur in $50 \%$ of melanoma and among the BRAF mutations observed in melanoma, over $90 \%$ are at codon 600 (3). Although, drugs targeting BRAF mutations, such as vemurafenib and dabrafenib, have been developed, clinical results with molecular targeted and also recently developed immunotherapeutic agents have not had satisfactory results. Consequently, a deeper understanding of the molecular biology of melanoma has been

Correspondence to: Dr Satoru Yokoyama, Division of Pathogenic Biochemistry, Institute of Natural Medicine, University of Toyama, 2630 Sugitani, Toyama 930-0194, Japan

E-mail: yokoyama@inm.u-toyama.ac.jp

Key words: Coptidis Rhizoma, apoptosis, BAX/BAK, melanoma recognized as critical for progressively identifying therapeutic targets and novel treatment approaches (4).

Apoptosis is a process of programmed cell death that occurs in multicellular organisms. Defective apoptotic processes have been implicated in a wide variety of diseases, including cancer. Drugs or treatment strategies that can restore the apoptotic signaling pathways towards normality have the potential to eliminate cancer cells. Thus, the mechanisms underlying apoptosis are crucial and help in the understanding of the pathogenesis of dysregulated apoptosis (5).

One of the best understood activation mechanisms of apoptosis is the intrinsic pathway, which is regulated by BCL-2 family proteins (6). The BCL-2 family is composed of three functionally distinct groups: anti-apoptotic proteins (BCL-2, BCL-xL, MCL1, BCL-w and BCL2A1), multi-domain pro-apoptotic proteins (BAX and BAK) and BH3-only pro-apoptotic proteins (BIM, BID, PUMA, BAD and NOXA) (6). These three groups are functionally associated with each other; in other words, the anti-apoptotic proteins prevent apoptosis by neutralizing the $\mathrm{BH} 3$-only pro-apoptotic proteins that can directly activate pro-apoptotic proteins BAX and BAK, and thereby restrain their pro-apoptotic activity (7). In addition, BAK is inhibited predominantly by BCL-xL, MCL1 and BCL2A1, whereas BAX can be inhibited by all of the pro-survival proteins $(8,9)$. Both BAX and BAK have pore-forming activities that mediate the release of apoptotic molecules, such as Smac and cytochrome $c$, from the mitochondria into the cytosol (10), which triggers caspase-mediated apoptosis (11).

Coptidis Rhizoma, called 'Oren' in Japanese, is a herbal medicine used for the treatment of damp-heat syndromes (12). Its major active component, berberine, has drawn extensive attention due to the anticancer effects, which are related to the effects of these traditional herbs in the treatment of diseases by removing damp-heat and purging fire and counteracting toxicity (13). Coptidis Rhizoma water extracts (CR) has been reported to exhibit anticancer activity in human pancreatic and liver cancer and leukemia $(14,15)$. Yet, the underlying mechanisms have not been well understood.

In the present study, we examined the effect of CR on human melanoma cells. We showed that CR triggered apoptosis in human melanoma cells through the mitochondrial apoptotic pathway. The anti-apoptotic BCL-2 family proteins, BCL2A1, MCL1 and BCL-w, played an important role in activating the multi-domain pro-apoptotic proteins BAX and BAK induced by CR. 


\section{Materials and methods}

Cell culture and herbal medicine extraction. Human melanoma cell lines, A2058, UACC257, UACC62, MeWo, SK-Mel-2, M14, Malme3M and mouse fibroblast cells, NIH3T3, were cultured in RPMI-1640 medium (Invitrogen, Carlsbad, CA, USA) with $10 \%$ fetal bovine serum (FBS; ICN, Biomedicals, Inc., Aurora, OH, USA), $1 \mathrm{mM}$ L-glutamine (Invitrogen), $100 \mathrm{U} / \mathrm{ml}$ penicillin, and $100 \mu \mathrm{g} / \mathrm{ml}$ streptomycin in a humidified atmosphere of $95 \%$ air and $5 \% \mathrm{CO}_{2}$ at $37^{\circ} \mathrm{C}$.

The crude Coptidis Rhizoma was added to an appropriate volume of distilled water (v/v, 1:8) and boiled under a low flame for $50 \mathrm{~min}$. The extract was filtered and then freeze-dried to obtain dried powder. The voucher sample of CR (INM_ID: 00000052; University of Toyama, Toyama, Japan) was preserved at the Cooperative Research Project by the Joint Usage/Research Center, Institute of Natural Medicine, University of Toyama. After reconstitution, CR was dissolved in water. Berberine chloride hydrate was purchased from Wako Pure Chemical Industries, Ltd. (Osaka, Japan).

Annexin V/7-AAD staining. Apoptotic cell numbers were determined using the Muse Annexin V and Dead Cell kit (Merck Millipore, Hayward, CA, USA) according to the manufacturer's instructions. After treatment with CR $(100 \mu \mathrm{g} / \mathrm{ml})$ for $24 \mathrm{~h}$, all cells were collected and diluted with phosphatebuffered saline (PBS) containing $1 \%$ BSA as a dilution buffer to a concentration of $5 \times 10^{5}$ cells $/ \mathrm{ml}$. Then, $100 \mu \mathrm{l}$ of cell suspension was added to $100 \mu \mathrm{l}$ Muse Annexin V and Dead Cell reagent, incubated for $20 \mathrm{~min}$ at room temperature, and analyzed using the Muse Cell Analyzer (Merck Millipore).

Western blotting. Whole cell lysates were prepared as previously described (16). Primary antibodies used were BAX (D2E11) (\#5023), BAK (D4E4) (\#12105), PARP (\#9542), BCL-w (31H4) (\#2724), MCL1 (D35A5) (\#5453), A1/Bfl-1 (\#4647), BCL-xL (54H6) (\#2746), and BCL-2 (50E3) (\#2870) purchased from Cell Signaling Technology, Inc. (Beverly, MA, USA), and the primary dilution was performed at 1:1,000. $\alpha$-tubulin (T9026) was purchased from Sigma-Aldrich Company (St. Louis, MO, USA), and the primary dilution was performed at 1:2,000.

Measurement of caspase activity. For measurement of the activities of caspase- 3 and -7 , the Caspase-Glo ${ }^{\circledR}$ 3/7 assay was carried out according to the manufacturer's instructions. This kit is based on the cleavage of the amino acid sequence DEVD of a luminogenic substrate by caspase- 3 and -7 , which results in a luminescent signal. Human melanoma cells in exponential growth were placed at a final concentration of $5 \times 10^{3}$ cells $/ 90 \mu \mathrm{l} /$ well in a white-walled multiwell plate. The cells were treated with CR $(100 \mu \mathrm{g} / \mathrm{ml})$ or with the vehicle for another $18 \mathrm{~h}$. Then, $100 \mu \mathrm{l}$ of Caspase-Glo ${ }^{\circledR}$ 3/7 reagent was added, and the plates were incubated for another $30 \mathrm{~min}$. Caspase- 3 and -7 activities were recorded using a GloMax-Multi Detection system.

Isolation of mitochondrial and cytosolic protein. The mitochondrial and cytosolic fractions were isolated using Mitochondria/Cytosol Fractionation kit (Abcam) according to the manufacturer's instructions. Briefly, CR-treated melanoma cells were harvested, and then washed in $10 \mathrm{ml}$ ice-cold PBS.
After removing the supernatant, the cells were re-suspended in $1 \mathrm{ml} 1 \mathrm{X}$ Cytosol Extraction Buffer Mix containing DTT and protease inhibitors, incubated for $10 \mathrm{~min}$ on ice, homogenized, and centrifuged at $700 \mathrm{x} \mathrm{g}$ for $10 \mathrm{~min}$. The supernatant was centrifuged again at $13,000 \mathrm{x}$ f for $30 \mathrm{~min}$. The remaining supernatant was the cytosolic fraction, and the pellet re-suspended with Mitochondrial Extraction Buffer Mix containing DTT and protease inhibitors was the mitochondrial fraction. The final result was performed with western blotting.

Real-time RT-PCR. Total RNAs were prepared using the RNeasy Plus Mini kit (Qiagen, Hilden, Germany) and subjected to real-time PCR on an ABI Prism 7300 sequence detection system (Life Technologies Corporation, Carlsbad, CA, USA). The expression levels of $M C L 1, B C L 2 A 1, B C L-w$ and MITF mRNAs were normalized to $\beta$-actin mRNA. The primers used were: 5'-TCG TAA GGA CAA AAC GGG AC-3' (sense) and 5'-CAT TCC TGA TGC CAC CTT CT-3' (antisense), for MCL1 mRNA; 5'-CCC GGA TGT GGA TAC CTA TAA GGA GA-3' (sense) and 5'-GTC ATC CAG CCA GAT TTA GGT TCA-3' (antisense), for BCL2A1 mRNA; 5'-TCA ACA AGG AGA TGG AAC CAC-3' (sense) and 5'-ATA GAG CTG TGA ACT CCG CC-3' (antisense), for $B C L-w$ mRNA; 5'-GTC ATC CAG CCA GAT TTA GGT TCA-3' (sense) and 5'-CAT TGT TAT GCT GGA AAT GCT AGA A-3' (antisense), for MITF mRNA; and 5'-GCA CAG AGC CTC GCC TT-3' (sense) and 5'-GTT GTC GAC GAC GAG CG-3' (antisense), for $\beta$-actin mRNA.

Cell viability assay. Cell viability was measured using CellTiter-Glo 2.0 assay (Promega Corporation, Madison, WI, USA) according to the manufacturer's instructions. Briefly, melanoma cells were seeded into 96-well plates $\left(5-10 \times 10^{3}\right.$ cells $/ 90 \mu \mathrm{l} /$ well) and incubated overnight. They were further cultured with CR (50 or $100 \mu \mathrm{g} / \mathrm{ml}$ ) or berberine $(12.5$ or $25 \mu \mathrm{M})$ for 24,48 and $72 \mathrm{~h}$, and lysed with firefly luciferase reagents. The luciferase activity was measured by GloMax Multi-detection system (Promega).

Intracellular staining and flow cytometric analysis of BAK activation. A2058 melanoma cells were seeded into 6-well plates $\left(2 \times 10^{5} / 2 \mathrm{ml} /\right.$ well $)$ and incubated overnight. They were further cultured with CR $(100 \mu \mathrm{g} / \mathrm{ml})$ for $24 \mathrm{~h}$. After being harvested and washed by PBS, the cells were fixed and permeabilized by adding Fixation/Permeabilization solution (BD Cytofix/Cytoperm ${ }^{\mathrm{TM}}$ Fixation/Permeabilization kit; BD Biosciences, Franklin Lakes, NJ, USA) for $20 \mathrm{~min}$ at $4^{\circ} \mathrm{C}$ (500 $\mu \mathrm{l} /$ tube). After washing twice with Perm/Wash buffer (BD Biosciences), the cells were incubated with anti-BAK (Ab-1) Mouse mAb (AM03, Merck) (1:50) for $1 \mathrm{~h}$ at room temperature. After washing with Perm/Wash buffer twice, cells were incubated with FITC-labeled anti-mouse antibody (F0313, DAKO) (1:25) for $1 \mathrm{~h}$ at room temperature. Finally, the stained cells ( $1 \times 10^{4} /$ sample) were analyzed on a BD Accuri C6 flow cytometer (BD Biosciences). For quantitation and comparison, the median of the fluorescence intensity values was calculated using FlowJo software.

Establishment of $A 2058 \mathrm{BAX}^{-/-}$and $\mathrm{BAK}^{-/-}$melanoma cell lines. For knocking out BAX or BAK, the target sequences 

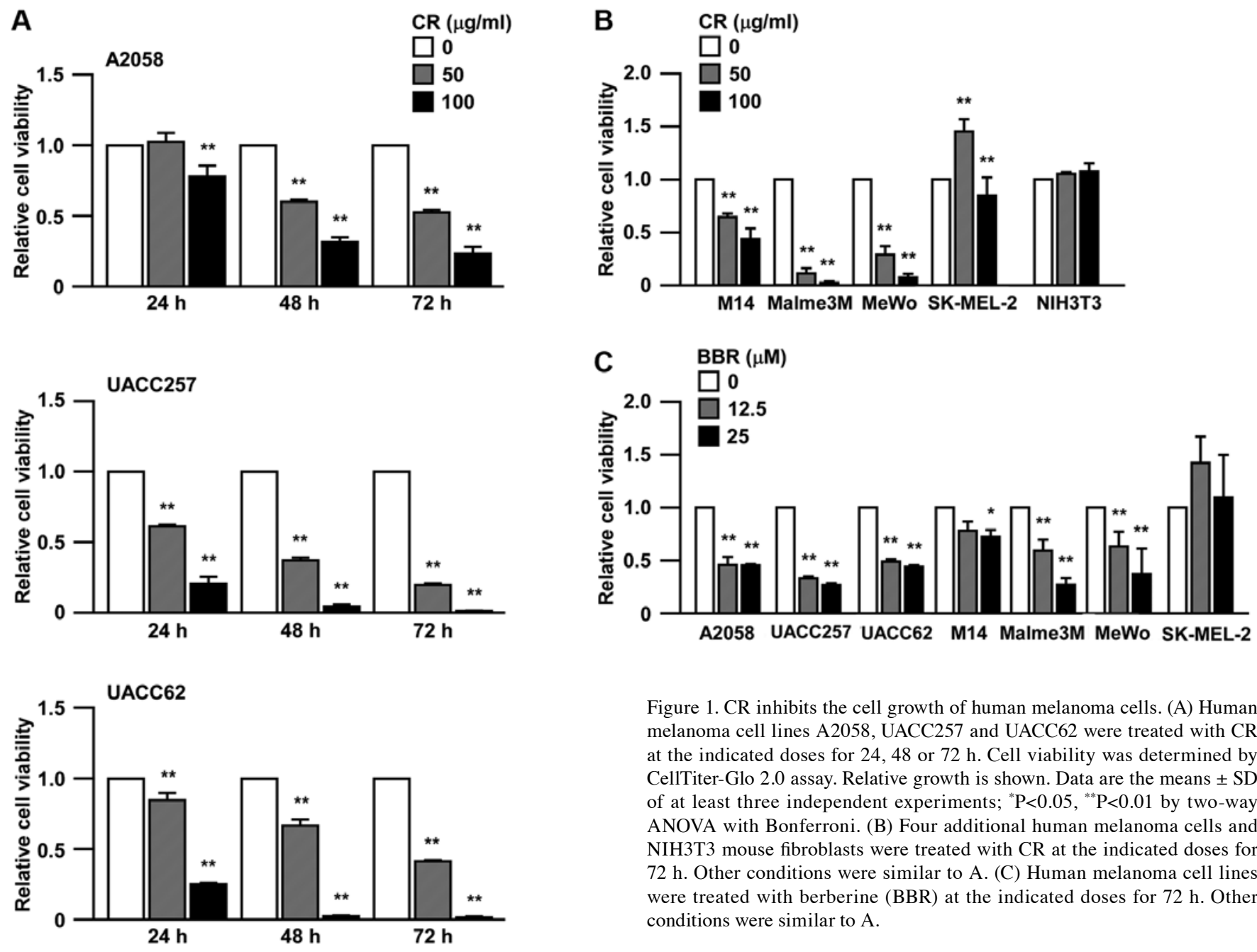

Figure 1. CR inhibits the cell growth of human melanoma cells. (A) Human melanoma cell lines A2058, UACC257 and UACC62 were treated with CR at the indicated doses for 24,48 or $72 \mathrm{~h}$. Cell viability was determined by CellTiter-Glo 2.0 assay. Relative growth is shown. Data are the means \pm SD of at least three independent experiments; ${ }^{*} \mathrm{P}<0.05,{ }^{* *} \mathrm{P}<0.01$ by two-way ANOVA with Bonferroni. (B) Four additional human melanoma cells and NIH3T3 mouse fibroblasts were treated with $\mathrm{CR}$ at the indicated doses for $72 \mathrm{~h}$. Other conditions were similar to A. (C) Human melanoma cell lines were treated with berberine (BBR) at the indicated doses for $72 \mathrm{~h}$. Other conditions were similar to A.

containing the PAM sequences were inserted into GeneArt CRISPR nuclease vector with OFP (Life Technologies, Gaithersburg, MD, USA). The inserted sequences used were: 5'-AAG GAC GAA ACA CCG TCT GGG CTT CGG CTA CCG TCG TTT TAG AGC TAG AA-3' for BAK; and 5'-AAG GAC GAA ACA CCG CCG AGA GGT CTT TTT CCG AGG TTT TAG AGC TAG AA-3' for BAX.

For the establishment of BAX- or BAK-knockout cells, A2058 cells were transfected with GeneArt CRISPR nuclease vector containing BAX or BAK and selected by FACS sorting methods. After single cell cloning, the targeted sequences were confirmed by sequencing.

Statistical analysis. Statistical significance was calculated using Excel software (Microsoft Corporation, Redmond, WA, USA). More than three means were compared using two-way analysis of variance (ANOVA) with Bonferroni correction. $\mathrm{P}<0.05$ was considered statistically significant.

\section{Results}

$C R$ inhibits the cell viability in some melanoma cell lines. We first tested the inhibitory effects on cell viability following CR treatment in three human melanoma cell lines with BRAF V600E mutation, A2058, UACC257 and UACC62.
After treatment with $\mathrm{CR}$, the cell viability was significantly reduced in a dose- and time-dependent manner in all three cell lines (Fig. 1A), similar to other cancers after treatment of $100 \mu \mathrm{g} / \mathrm{ml} \mathrm{CR}$ (17-19). In addition, we assessed the cell viability in other melanoma cell lines, M14 (BRAF V600E), Malme3M (BRAF V600E), MeWo (no mutation in BRAF and NRAS), and SK-MEL-2 (NRAS Q61R), with a different genetic background (Fig. 1B). Except SK-MEL-2, the cell viability was strongly inhibited by CR in M14, Malme3M and MeWo cell lines. The growth inhibition by CR was not detected in NIH3T3 mouse fibroblast cells. We also used one of the major components of $\mathrm{CR}$, berberine (BBR), to treat the melanoma cells (Fig. 1C). BBR also inhibited the melanoma cell viability except for SK-MEL-2 cells.

CR induces apoptosis in human melanoma cells. To investigate whether or not the suppression of cell viability by CR was attributed to apoptosis, we examined the apoptotic cells using flow cytometric analysis with Annexin V staining (Fig. 2A). Strikingly, in all three human melanoma cell lines, the number of Annexin V-positive cells was significantly increased by CR. Furthermore, we also detected the induction of cleavages of PARP by CR in all melanoma cell lines (Fig. 2B) and the activation of caspases by CR using luciferase-based methods (Fig. 2C). These data suggest that the inhibition of 
A

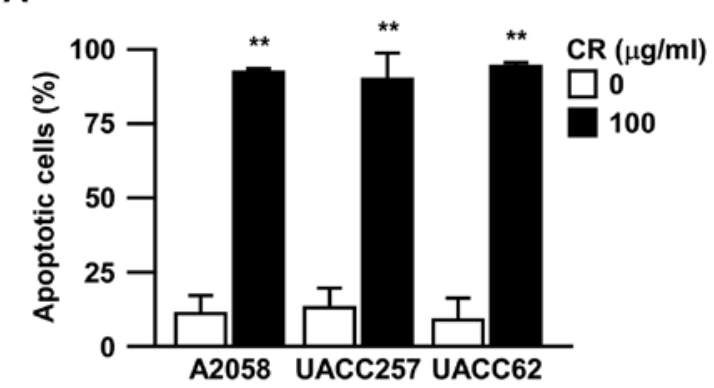

B

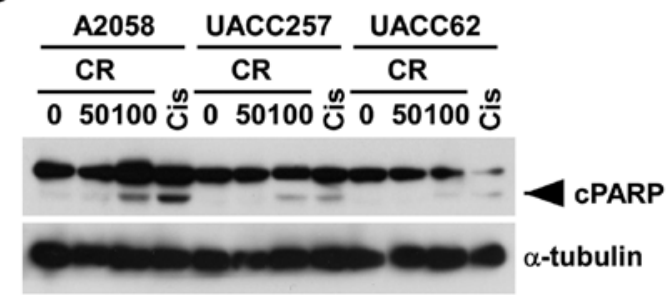

C

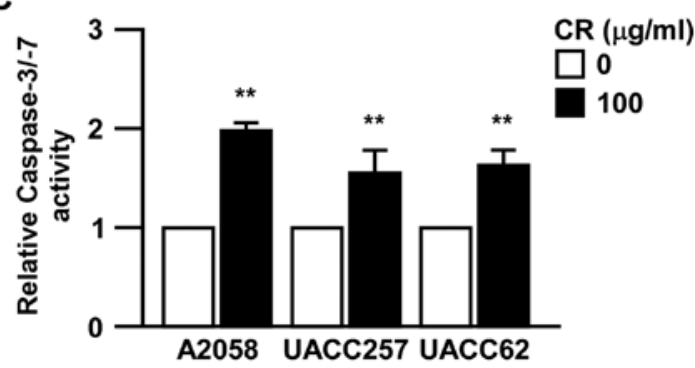

Figure 2. CR induces apoptosis in human melanoma cells. (A) A2058, UACC257 and UACC62 cells were treated with $100 \mu \mathrm{g} / \mathrm{ml} \mathrm{CR}$ for $24 \mathrm{~h}$. The percentages of apoptotic cells were determined as Annexin V-stained cells using flow cytometry. Data are the means \pm SD of at least three independent experiments; ${ }^{* *} \mathrm{P}<0.01$ by one-way ANOVA with Bonferroni. (B) A2058, UACC257 and UACC62 cells were treated with 50 and $100 \mu \mathrm{g} / \mathrm{ml} \mathrm{CR}$ and $20 \mu \mathrm{M}$ cisplatin (Cis) for $24 \mathrm{~h}$. Whole cell lysates were subjected to western blotting and cleaved PARP (cPARP) was detected. Cisplatin is regarded as a positive control for apoptosis. (C) A2058, UACC257 and UACC62 were treated with $100 \mu \mathrm{g} / \mathrm{ml} \mathrm{CR}$ for $18 \mathrm{~h}$. The activities of caspases were measured by Caspase-Glo 3/7 assay and normalized to the vehicle control. Data are the means \pm SD of at least three independent experiments; ${ }^{* *} \mathrm{P}<0.01$ by two-way ANOVA using Bonferroni.

cell viability by $\mathrm{CR}$ may be mediated largely through the induction of caspase-mediated apoptosis.

$C R$ induces apoptosis by inhibiting the anti-apoptotic proteins, MCL1, BCL2A1 and BCL-w in human melanoma cells. Given that certain crude extracts from natural medicines induce apoptosis through the intrinsic pathway $(20,21)$, we next determined the involvement of anti-apoptotic BCL-2 family members, including BCL2, BCL-xL, BCL-w, MCL1 and BCL2A1, in CR-induced apoptosis (Fig. 3A). Although BCL2 and BCL-xL were not affected, the protein levels of anti-apoptotic proteins, MCL1 and BCL2A1, were consistently suppressed by $\mathrm{CR}$ in all three cell lines in a dose-dependent manner. In the case of BCL-w, UACC257 and UACC62 cells showed suppression by CR at $24 \mathrm{~h}$, but A2058 cells did not. When A2058 cells were treated with CR for $48 \mathrm{~h}$, the suppression of BCL-w was detected (Fig. 3B). In the case of multi-domain pro-apoptotic proteins of the BCL-2 family,
BAX and BAK, their protein expression levels did not show any significant change by $\mathrm{CR}$ treatment (Fig. 3A). In addition, we assessed the effects of BBR on anti-apoptotic BCL-2 family members. MCL1 and BCL2A1 were suppressed by BBR, although BCL-w was not suppressed in the A2058 and UACC257 cells (Fig. 3C). Consistently, we detected the suppression of mRNA levels of MCL1, BCL2A1 and BCL-w, in all three cell lines (Fig. 3D). This suggests that CR may induce apoptosis by suppressing the mRNA expression of $M C L 1, B C L 2 A 1$ and $B C L-w$ in human melanoma cells.

$C R$-induced apoptosis is mediated through the activation of $B A X / B A K$. To investigate the responsible effectors of BCL2 family by $\mathrm{CR}$, we focused on multi-domain pro-apoptotic proteins of the BCL-2 family, BAX and BAK, both of which were not affected by $\mathrm{CR}$ at their protein levels (Fig. 3A). These two proteins have pore-forming activities that mediate the release of apoptotic molecules, such as Smac and cytochrome $c$ (10). BAX has been known as a cytosolic protein, which translocates to mitochondria during its activation (22). In contrast, BAK is expressed on the mitochondrial membrane and shows a conformational change during its activation, which is recognized by a specific antibody (23). As shown in Fig. 4A, BAX translocation from the cytosol to mitochondria was induced by $\mathrm{CR}$, although BAK only existed in the mitochondrial fraction, not in the cytosolic fraction. However, BAK conformational change was also detected following CR treatment by intracellular staining using a specific antibody, which specifically detects the conformational change of BAK (Fig. 4B). These results suggest that $\mathrm{CR}$ activated both BAX and BAK in human melanoma cells. Furthermore, to check the significance of BAX/BAK, we established A2058 cell lines with knockout of BAX or BAK (named A2058 $\mathrm{BAX}^{-/}$and A2058 $\mathrm{BAK}^{-/}$, respectively) (Fig. 4C) and treated these established cell lines with CR. As shown in Fig. 4D, both A2058 $\mathrm{BAK}^{-/-}$and A2058 BAX ${ }^{-/}$increased their cell viability following treatment with $\mathrm{CR}$. In addition, PARP cleavage was significantly reduced in both A2058 $\mathrm{BAK}^{-/-}$and A2058 $\mathrm{BAX}^{-/}$cell lines, compared with the A2058 parental cells (Fig. 4E). These results strongly support that both BAX and BAK are required for $\mathrm{CR}$-induced apoptosis.

\section{Discussion}

In the present study, we determined that Coptidis Rhizoma water extract (CR) suppressed cell viability through the induction of apoptosis in human melanoma. In addition, the apoptosis was mediated through the suppression of BCL-w, MCL1 and BCL2A1, resulting in the activation of BAX/BAK.

$\mathrm{CR}$ and its active component berberine (BBR) have been revealed as having cytotoxicity effects on various types of cancer such as breast, colon and lung (24-26). Although BBR is the major anticancer component in CR, some studies have reported that CR may be more effective than BBR alone $(14,27)$. In the present study, both BBR and CR suppressed cell growth in the human melanoma cells (Fig. 1), although their effects on BCL-w protein were different (Fig. 3). This implies that the underlying mechanisms of CR may be complicated and that BBR alone may not be sufficient to understand the mechanisms of actions of CR. Further investigation is required for identifying the active component in CR with anticancer activity; in 
A

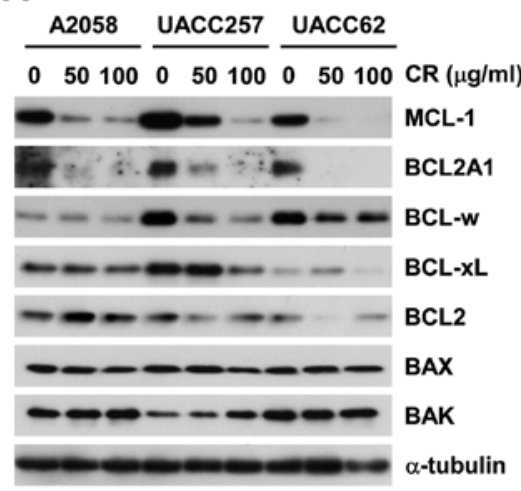

B

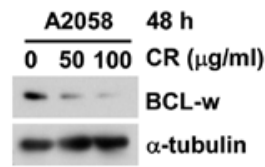

C

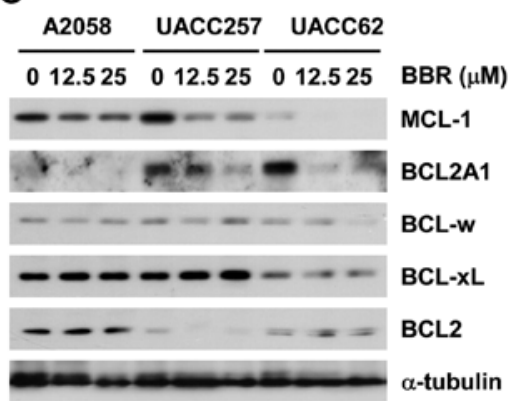

D
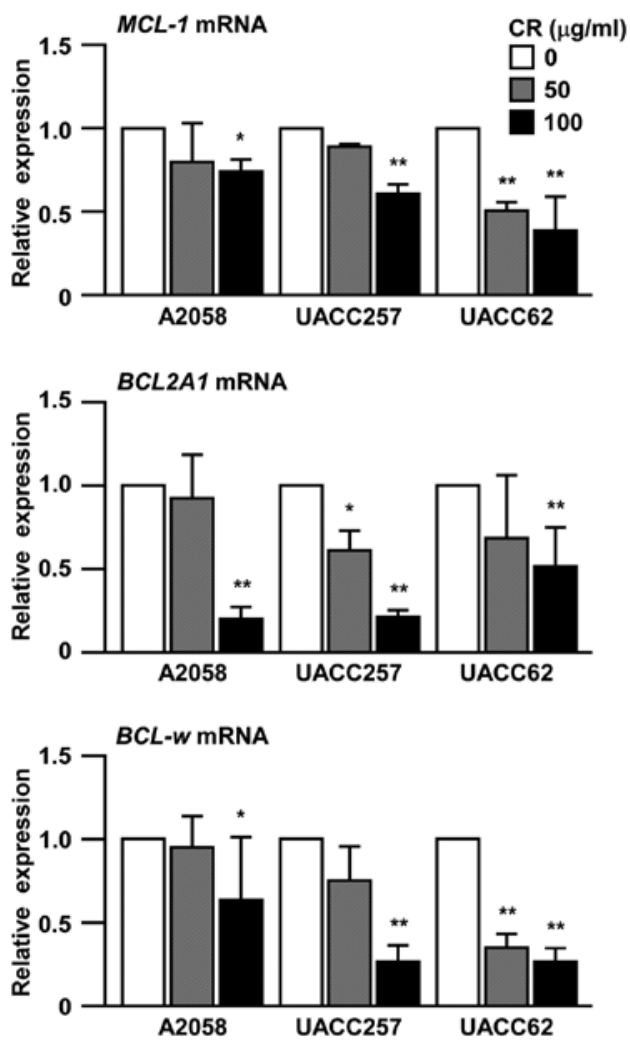

Figure 3. CR induces apoptosis by inhibiting the anti-apoptotic proteins, MCL1, BCL2A1 and BCL-w in human melanoma cells. (A) A2058, UACC257 and UACC62 cells were treated with 50 and $100 \mu \mathrm{g} / \mathrm{ml} \mathrm{CR}$ for $24 \mathrm{~h}$. Whole cell lysates were subjected to western blotting. (B) A2058 cells were treated with 50 and $100 \mu \mathrm{g} / \mathrm{ml} \mathrm{CR}$ for $48 \mathrm{~h}$. Whole cell lysates were subjected to western blotting. (C) A2058, UACC257 and UACC62 cells were treated with berberine (BBR) at the indicated doses for $24 \mathrm{~h}$. Other conditions were similar to A. (D) A2058, UACC257 and UACC62 cells were treated with 50 and $100 \mu \mathrm{g} / \mathrm{ml} \mathrm{CR}$ for $24 \mathrm{~h} . M C L 1, B C L 2 A 1$ and $B C L-w$ mRNA were quantified by real-time RT-PCR. Relative mRNA expression was normalized to the value of each mRNA at 0 h. Data are shown as the mean $\pm \mathrm{SD}$ of three independent experiments; " $\mathrm{P}<0.05$ or ${ }^{* *} \mathrm{P}<0.01$ by two-way ANOVA using Bonferroni.

A
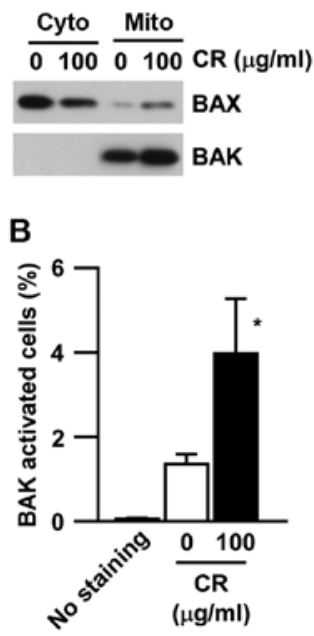

C

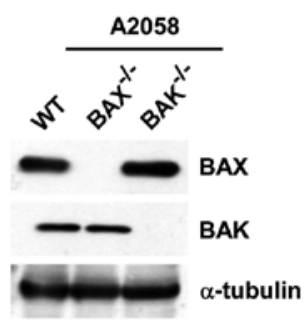

E

Figure 4. CR-induced apoptosis is mediated through the activation of BAX/BAK. (A) A2058 melanoma cells were treated with $100 \mu \mathrm{g} / \mathrm{ml} \mathrm{CR}$ for $24 \mathrm{~h}$. The mitochondrial fraction (Mito) and cytosolic fraction (Cyto) of these cells were isolated and subjected to western blotting. (B) A2058 melanoma cells treated with $100 \mu \mathrm{g} / \mathrm{ml} \mathrm{CR}$ for $24 \mathrm{~h}$ were fixed, permeabilized, and stained using the antibody recognizing the conformational change of BAK. BAK-activating cells were analyzed on a flow cytometer. Data are shown as the means \pm SD of at least three independent experiments; ${ }^{*} \mathrm{P}<0.05$ by one-way ANOVA with Bonferroni. (C) A2058 melanoma cells with BAX and BAK knockout were subjected to western blotting. (D) A2058 melanoma cells with BAX and BAK knockout were treated with 50 and $100 \mu \mathrm{g} / \mathrm{ml} \mathrm{CR}$ for $24 \mathrm{~h}$. Cell viability was determined by CellTiter-Glo 2.0 assay. Relative growth is shown. Data are the means \pm SD of at least three independent experiments; ${ }^{\# \#} \mathrm{P}<0.01$ by two-way ANOVA using Bonferroni compared with the parent A2058 cells treated with each concentration of CR. (E) Whole cell lysates were subjected to western blotting. Other conditions were similar to D. 
other words, CR itself or traditional Kampo/Chinese medicines containing CR may be applicable for melanoma, although its mechanism of action has not been determined in detail.

We identified that CR suppressed MCL1, BCL2A1 and BCL-w in human melanoma cells (Fig. 3A). It has been reported that MCL1 is known as an oncogene which is commonly amplified in various types of cancers, and that MCL1-amplified cancer is more sensitive to MCL1 suppression (28). In contrast, BCL2A1 has been confirmed as a lineage-specific anti-apoptotic melanoma oncogene with amplification, which confers resistance toBRAF inhibition (29). In addition, BCL2A1 is also regulated by the melanoma-specific oncogene, MITF, which is also amplified specifically in melanoma UACC62 and UACC257 cells (30). In the present study, MITF mRNA and protein were also suppressed by CR (data not shown), supporting the functional significance of the MITF/BCL2A1 axis in CR-induced apoptosis. Various studies indicate that inhibition of both MCL1 and BCL2A1 expression could lead to $\sim 70 \%$ cell death in melanoma cells, which achieves better anticancer effects $(8,31,32)$. In the human melanoma cells used, only SK-MEL-2 was relatively insensitive to CR (Fig. 1), which does not have any gene copy number alteration in the $M C L 1, B C L 2 A 1$ and MITF regions. In addition, the effects of CR or BBR on NRAS-mutant melanoma cells including SK-MEL-2 cells remain to be further investigated since only NRAS-mutant melanoma showed the induction of cell growth at a lower dose of CR and BBR. Collectively, BCL2A1 and $M I T F$ amplification are specific to melanoma, thus CR may be applicable for other cancer patients with MCL1 amplification.

Anticancer drugs, such as cisplatin, exhibit high cytotoxicity even in normal cells. CR does not show any adverse side-effects, which is supported historically and clinically by its usage for $>2,000$ years as a traditional Kampo medicine in Japan or traditional Chinese medicine in China. However, in addition to cytotoxicity, many other pharmacological effects of CR have been reported including anti-inflammation, antiinfection and anti-hypertension (13). In addition, CR and BBR prevent cachexia (33), which is characterized by profound weight loss, anorexia, and weakness. Thus, CR and other traditional Kampo/Chinese medicines containing CR may be useful as anticancer drugs or as adjuvant therapeutic agents.

In summary, we demonstrated that CR induced apoptosis by BAX and BAK activation in human melanoma cells, which was mediated through the suppression of MCL1, BCL2A1 and BCL-w. This natural herbal medicine, CR or various formulations containing $\mathrm{CR}$ may constitute an effective and safe treatment for human melanoma.

\section{Acknowledgements}

The present study was supported in part by Grant-in-Aid 16K18413 for Young Scientists (B) (S.Y.) and by Grant-in-Aid $15 \mathrm{~K} 08902$ for Scientific Research (C) (I.S.) from the Ministry of Education, Culture, Sports, Scienceand Technology (Japan), and The Uehara Memorial Foundation (S.Y.).

\section{References}

1. Liu J, Fukunaga-Kalabis M, Li L and Herlyn M: Developmental pathways activated in melanocytes and melanoma. Arch Biochem Biophys 563: 13-21, 2014.
2. Siegel RL, Miller KD and Jemal A: Cancer statistics, 2016. CA Cancer J Clin 66: 7-30, 2016.

3. Ascierto PA, Kirkwood JM, Grob JJ, Simeone E, Grimaldi AM, Maio M, Palmieri G, Testori A, Marincola FM and Mozzillo N: The role of BRAF V600 mutation in melanoma. J Transl Med 10: $85,2012$.

4. Karachaliou N, Pilotto S, Teixidó C, Viteri S, González-Cao M, Riso A, Morales-Espinosa D, Molina MA, Chaib I, Santarpia M, et al: Melanoma: Oncogenic drivers and the immune system. Ann Transl Med 3: 265, 2015.

5. Wong RS: Apoptosis in cancer: From pathogenesis to treatment. J Exp Clin Cancer Res 30: 87, 2011.

6. Juin P, Geneste O, Gautier F, Depil S and Campone M: Decoding and unlocking the BCL-2 dependency of cancer cells. Nat Rev Cancer 13: 455-465, 2013.

7. Czabotar PE, Lessene G, Strasser A and Adams JM: Control of apoptosis by the BCL-2 protein family: Implications for physiology and therapy. Nat Rev Mol Cell Biol 15: 49-63, 2014.

8. Simmons MJ, Fan G, Zong WX, Degenhardt K, White E and Gélinas C: Bfl-1/A1 functions, similar to Mcl-1, as a selective tBid and Bak antagonist. Oncogene 27: 1421-1428, 2008.

9. Willis SN, Chen L, Dewson G, Wei A, Naik E, Fletcher JI, Adams $\mathrm{M}$ and Huang DC: Proapoptotic Bak is sequestered by Mcl-1 and Bcl-xL, but not Bcl-2, until displaced by BH3-only proteins. Genes Dev 19: 1294-1305, 2005.

10. Hartman ML and Czyz M: Anti-apoptotic proteins on guard of melanoma cell survival. Cancer Lett 331: 24-34, 2013.

11. Fischer U, Jänicke RU and Schulze-Osthoff K: Many cuts to ruin: A comprehensive update of caspase substrates. Cell Death Differ 10: 76-100, 2003.

12. Wang N, Tan HY, Li L, Yuen MF and Feng Y: Berberine and Coptidis Rhizoma as potential anticancer agents: Recent updates and future perspectives. J Ethnopharmacol 176: 35-48, 2015.

13. Tang J, Feng Y, Tsao S, Wang N, Curtain R and Wang Y: Berberine and Coptidis Rhizoma as novel antineoplastic agents: A review of traditional use and biomedical investigations. $J$ Ethnopharmacol 126: 5-17, 2009

14. Hara A, Iizuka N, Hamamoto Y, Uchimura S, Miyamoto T, Tsunedomi R, Miyamoto K, Hazama S, Okita K and Oka M: Molecular dissection of a medicinal herb with anti-tumor activity by oligonucleotide microarray. Life Sci 77: 991-1002, 2005.

15. Lin CC, Ng LT, Hsu FF, Shieh DE and Chiang LC: Cytotoxic effects of Coptis chinensis and Epimedium sagittatum extracts and their major constituents (berberine, coptisine and icariin) on hepatoma and leukaemia cell growth. Clin Exp Pharmacol Physiol 31: 65-69, 2004.

16. Sakurai H, Suzuki S, Kawasaki N, Nakano H, Okazaki T, Chino A, Doi T and Saiki I: Tumor necrosis factor-alphainduced IKK phosphorylation of NF-kappaB p65 on serine 536 is mediated through the TRAF2, TRAF5, and TAK1 signaling pathway. J Biol Chem 278: 36916-36923, 2003.

17. Kim YJ, Kang SA, Hong MS, Park HJ, Kim MJ, Park HJ and Kim HK: Coptidis Rhizoma induces apoptosis in human colorectal cancer cells SNU-C4. Am J Chin Med 32: 873-882, 2004.

18. Liu J, He C, Zhou K, Wang J and Kang JX: Coptis extracts enhance the anticancer effect of estrogen receptor antagonists on human breast cancer cells. Biochem Biophys Res Commun 378: 174-178, 2009.

19. Tan HY, Wang N, Tsao SW, Zhang Z and Feng Y: Suppression of vascular endothelial grow th factor via inactivation of eukaryotic elongation factor 2 by alkaloids in Coptidis rhizome in hepatocellular carcinoma. Integr Cancer Ther 13: 425-434, 2014.

20. Cao C, Liu B, Zeng C, Lu Y, Chen S, Yang L, Li B, Li Y and Li Y: A polymethoxyflavone from Laggera pterodonta induces apoptosis in imatinib-resistant K562R cells via activation of the intrinsic apoptosis pathway. Cancer Cell Int 14: 137, 2014.

21. Kim MJ, Kwon SB, Ham SH, Jeong ES, Choi YK, Choi KD, Hong JT, Jung SH and Yoon DY: H9 inhibits tumor growth and induces apoptosis via intrinsic and extrinsic signaling pathway in human non-small cell lung cancer xenografts. J Microbiol Biotechnol 25: 648-657, 2015.

22. Tikhomirov $\mathrm{O}$ and Carpenter $\mathrm{G}$ : Bax activation and translocation to mitochondria mediate EGF-induced programmed cell death. J Cell Sci 118: 5681-5690, 2005.

23. Pichichero E,Cicconi R, Mattei M and Canini A: Chrysin-induced apoptosis is mediated through $\mathrm{p} 38$ and Bax activation in B16-F1 and A375 melanoma cells. Int J Oncol 38: 473-483, 2011.

24. Kang JX, Liu J, Wang J, He C and Li FP: The extract of huanglian, a medicinal herb, induces cell growth arrest and apoptosis by upregulation of interferon-beta and TNF-alpha in human breast cancer cells. Carcinogenesis 26: 1934-1939, 2005. 
25. Peng PL, Hsieh YS, Wang CJ, Hsu JL and Chou FP: Inhibitory effect of berberine on the invasion of human lung cancer cells via decreased productions of urokinase-plasminogen activator and matrix metalloproteinase-2. Toxicol Appl Pharmacol 214: 8-15, 2006.

26. Wu K, Yang Q, Mu Y,Zhou L, Liu Y,Zhou Q and He B: Berberine inhibits the proliferation of colon cancer cells by inactivating Wnt/ $\beta$-catenin signaling. Int J Oncol 41: 292-298, 2012.

27. Li XK, Motwani M, Tong W, Bornmann W and Schwartz GK: Huanglian, A chinese herbal extract, inhibits cell growth by suppressing the expression of cyclin $\mathrm{B} 1$ and inhibiting CDC2 kinase activity in human cancer cells. Mol Pharmacol 58: 1287-1293, 2000.

28. Mukherjee N, Lu Y, Almeida A, Lambert K, Shiau CW, Su JC, Luo Y, Fujita M, Robinson WA, Robinson SE, et al: Use of a MCL-1 inhibitor alone to de-bulk melanoma and in combination to kill melanoma initiating cells. Oncotarget: Apr 12, 2016 (Epub ahead of print). doi: 10.18632 /oncotarget. 8695 .

29. Nessling M, Kern MA, Schadendorf D and Lichter P: Association of genomic imbalances with resistance to therapeutic drugs in human melanoma cell lines. Cytogenet Cell Genet 87: 286-290, 1999.
30. Haq R, Yokoyama S, Hawryluk EB, Jönsson GB, Frederick DT, McHenry K, Porter D, Tran TN, Love KT, Langer R, et al: $B C L 2 A 1$ is a lineage-specific antiapoptotic melanoma oncogene that confers resistance to BRAF inhibition. Proc Natl Acad Sci USA 110: 4321-4326, 2013

31. Chen L, Willis SN, Wei A, Smith BJ, Fletcher JI, Hinds MG, Colman PM, Day CL, Adams JM and Huang DC: Differential targeting of prosurvival $\mathrm{Bcl}-2$ proteins by their $\mathrm{BH} 3$-only ligands allows complementary apoptotic function. Mol Cell 17: 393-403, 2005.

32. Senft D, Berking C, Graf SA, Kammerbauer C, Ruzicka T and Besch R: Selective induction of cell death in melanoma cell lines through targeting of Mcl-1 and A1. PLoS One 7: e30821, 2012.

33. Iizuka N, Hazama S, Yoshimura K, Yoshino S, Tangoku A, Miyamoto K, Okita K and Oka M: Anticachectic effects of the natural herb Coptidis Rhizoma and berberine on mice bearing colon 26/clone 20 adenocarcinoma. Int J Cancer 99: 286-291, 2002 . 